\title{
Hogares guatemaltecos y etnicidad en el sur de México: perfiles demográficos y socioeconómicos
}

\section{Guatemalan households and ethnicity in the south of Mexico: Demographic and socioeconomic profiles}

Recibido el 24 de mayo de 2019.

Aceptado el 20 de noviembre de 2019.

Publicado el 9 de diciembre de 2019.

*Autor para correspondencia:

Eunice D. Vargas Valle,

correo electrónico,

eunice@colef.mx
Esta obra está protegida bajo una Licencia Creative Commons Atribución-NoComercial 4.0 Internacional.
Eunice D. Vargas Valle ${ }^{\text {** }}$ (D) https://orcid.org/0000-0002-6980-3077

Oscar Rodríguez Chávez ${ }^{b}$ (D) https://orcid.org/0000-0002-7255-0605

María Teresa Rodríguez López ${ }^{\mathrm{C}}$ (iD) https://orcid.org/0000-0001-6522-0408

${ }^{a}$ El Colegio de la Frontera Norte, México, correo electrónico: eunice@colef.mx

b El Colegio de México, México, correo electrónico: orodriguez@colmex.mx

${ }^{\mathrm{c}}$ Centro de Investigaciones y Estudios Superiores en Antropología Social, Unidad Golfo, México, correo electrónico: mtrguez@ciesas.edu.mx

\section{Resumen:}

El objetivo general de este artículo es analizar los perfiles demográficos y socioeconómicos de los hogares guatemaltecos por habla de lengua indígena en las entidades de la frontera sur de México. En particular, se explora cuántos hogares guatemaltecos están asentados, cómo se configuran y cómo se han integrado en términos estructurales, con base en la Encuesta Intercensal 2015. Para tal fin se emplea estadística descriptiva y un modelo de regresión logística multinomial. El análisis indica que los hogares guatemaltecos se concentran en áreas rurales, son numerosos y más jóvenes, y laboran principalmente en el sector primario. Su integración socioeconómica es desventajosa en rubros como las condiciones del empleo y de la vivienda y el acceso a servicios sociales. No obstante, los hogares guatemaltecos indígenas exhiben niveles más altos de integración social que sus contrapartes no indígenas en el acceso a la ciudadanía mexicana, vivienda y apoyos económicos gubernamentales.

Palabras clave: guatemaltecos, hogares, integración, migración, frontera sur, México.

Abstract:

The goal of this paper is to analyze the demographic and socioeconomic profiles of Guatemalan households by indigenous language in the southern border states of Mexico. In particular, it is explored how many Guatemalan households are settled, how they are configured and how they are integrated in structural terms, based on the Intercensus Survey 2015. To this end, descriptive statistics and a multinomial logistic model are used. The analysis indicates that Guatemalan households are concentrated in rural locali-

CÓMO CITAR: Vargas, E. D., Rodríguez, O. y Rodríguez, M. T. (2019). Hogares guatemaltecos y etnicidad en el sur de México: perfiles demográficos y socioeconómicos. [Guatemalan households and ethnicity in the south of Mexico: Demographic and socioeconomic profiles]. Estudios Fronterizos, 20, e036. doi:https://doi.org/10.21670/ref.1915036 
ties, are numerous and younger, and mainly work in the primary sector. Their socioeconomic integration is disadvantaged in aspects such as labor and housing conditions and access to social services. Nevertheless, Guatemalan indigenous households exhibit higher levels of social integration than their non-indigenous counterparts in the access to citizenship, housing and governmental economic transfers.

Keywords: Guatemalan population, households, integration, migration, southern border, Mexico.

\section{Introducción}

La frontera sur de México ha sido una zona de alta movilidad humana transfronteriza e internacional. Miles de guatemaltecos se han incorporado a algunos rubros productivos del sur mexicano, ya sea como trabajadores temporales fronterizos o como residentes permanentes (Meza, 2015). Entre las razones están las económicas, la aspiración por una vida mejor a través de la inserción laboral, pero también se ubican los motivos políticos o la violencia (González, 2015; Ramos, 2013). Así, en los años ochenta, miles de guatemaltecos obtuvieron refugio por estos motivos y decidieron permanecer en México tras los acuerdos de paz, quedándose a residir alrededor de los antiguos campamentos de refugio en distintos municipios de los estados del sur de México, y sobre todo, en los municipios colindantes de Chiapas con Guatemala (González, 2015; Kauffer, 2000; Ruiz, 2018).

Como resultado, los guatemaltecos han permeado la demografía de la frontera sur de México, al migrar con sus familiares o solos y establecer uniones conyugales con mexicanos, así como procrear hijos mexicanos por nacimiento. Aunque desde 2008 la presión de Estados Unidos se ha incrementado respecto a la aplicación de políticas de contención en esta frontera, los guatemaltecos han seguido llegando a México, como veremos más adelante. En el contexto del mayor control al cruce poblacional al norte de México y la creciente dificultad de migrar a Estados Unidos, la migración guatemalteca hacia y a través de México ha continuado (Rodríguez, 2016).

Este artículo tiene como objetivo general analizar los perfiles demográficos y socioeconómicos de los hogares guatemaltecos por condición de habla de lengua indígena en la frontera sur de México. En particular, interesa conocer cuántos hogares guatemaltecos están asentados, cómo se configuran y cómo se han integrado en términos estructurales, con base en la Encuesta Intercensal 2015, tomando en consideración las diferencias que pudieran registrarse por habla de lengua indígena, ya que es un elemento primordial del perfil sociodemográfico de los guatemaltecos en México, como veremos enseguida. Por integración estructural, entendemos el proceso por el cual se pueden alcanzar niveles similares de acceso a los mismos derechos, recursos, servicios e instituciones de los nativos como: empleo, educación, vivienda, sistema de salud y ciudadanía (Heckmann, 2003). Analizar la integración estructural es relevante, dado que esta determina el estatus socioeconómico y el bienestar social de los migrantes y sus descendientes (Esser, 2004).

Los pueblos indígenas históricamente se han caracterizado por vivir en condiciones de marginación a lo largo y ancho de América Latina (Del Popolo, 2017) y el hecho de ser migrantes podría poner a los guatemaltecos indígenas en doble desventaja, ya que 
ellos podrían estar quedando al margen de las políticas de desarrollo social dirigidas a los pueblos indígenas en México. Sin embargo, existe evidencia de que en el sur de México algunos guatemaltecos lograron tener acceso a tierras, infraestructura y opciones económicas diversificadas (Chan y García, 2018; Kauffer, 2000), mientras que otros desarrollaron estrategias de vida transfronteriza o transnacional (tanto con el país de origen como con los familiares guatemaltecos en Estados Unidos), las cuales favorecieron sus condiciones de vida, permitiéndoles aminorar riesgos sociales y económicos (Rodríguez y Caballeros, 2020; Ruiz, 2018).

Este artículo se elabora desde una visión sociodemográfica que considera al hogar como unidad de análisis. De manera general, el asentamiento de los guatemaltecos en México es visto como una estrategia de vida familiar ${ }^{1}$ que ha permitido su reproducción social y económica, así como su sobrevivencia (Torrado, 1981). Cabe señalar, que permanecer en México tras el fin de la guerra o migrar en búsqueda de empleo o reunificación familiar han sido decisiones de los individuos o las familias, las cuales han estado constreñidas por las estructuras de oportunidad. Así, el análisis de la configuración y las dinámicas de los hogares y sus vínculos con las estructuras sociales en determinado espacio geográfico es esencial, no solo porque permite conocer las condicionantes de las estrategias de reproducción familiar, sino porque sirve de base para el diseño de intervenciones públicas efectivas encaminadas al desarrollo social (López, 2001).

El artículo se compone de cuatro apartados. En el primero, se hace una breve revisión de la literatura sobre el asentamiento de guatemaltecos en el sur de México, con el fin de contextualizar el análisis sociodemográfico. En el segundo, se define la metodología empleada para el análisis. En el tercero, se describen la composición sociodemográfica de dichos hogares en 2015, así como sus niveles de bienestar social. Finalmente, se discuten los hallazgos y sus implicaciones para la política pública a favor de la integración socioeconómica de los inmigrantes guatemaltecos en México.

\section{Los guatemaltecos en México: Del refugio a la integración}

En este apartado se hace un sucinto recuento de la inmigración guatemalteca reciente en el sur de México para contextualizar el análisis de los perfiles demográficos y socioeconómicos. Se considera que la migración de hogares guatemaltecos a México es multicausal e histórica, por lo tanto, puede ser definida en distintos términos según se trate de la época del asentamiento (Del Popolo, 2017). Por ejemplo, en la época del conflicto armado en Guatemala la migración fue forzada. En la gran mayoría de los casos los destinos fueron fronterizos, algunos de origen común ancestral, y se diversificaron después con la reubicación de los migrantes refugiados en otras áreas no fronterizas de los estados de Chiapas, Campeche y Quintana Roo. No obstante, en corrientes sucesivas, la migración forzada por violencia coexistió con las migraciones

${ }^{1}$ Las estrategias podrían ser también individuales y el asentamiento asociarse a la formación familiar en México o desarrollarse en hogares no familiares. Sin embargo, la gran mayoría de los guatemaltecos incluidos en los censos poblacionales tienen vínculos familiares en este país, como se explica en la sección metodológica. 
transfronterizas o transnacionales en búsqueda de oportunidades laborales, sostenidas por redes sociales étnicas que mantienen intercambios entre los orígenes y los destinos. Para los fines de este artículo se habla de migración de guatemaltecos a México en general, sin distinguir las causas de la migración, a continuación se describe este proceso en esta zona de México.

En la historia de la migración México-Guatemala, los alcances y ritmos de la interacción fronteriza a partir de los años veinte del siglo xix han seguido las siguientes pautas: la incorporación a México de habitantes de las zonas limítrofes que pasaron a formar parte de territorio nacional en el contexto de las disputas y convenios fronterizos en el siglo xix; el asentamiento definitivo de jornaleros estacionales y campesinos establecidos en parajes limítrofes; el arribo de exiliados, asilados y refugiados durante las décadas de los sesenta a los ochenta del siglo xx; y el establecimiento de individuos y grupos familiares, favorecido por las redes de migrantes asentados previamente en México (Castillo y Vázquez, 2010, pp. 238-9).

En particular, la movilidad de guatemaltecos a México, principalmente en busca de trabajo en el sector agrícola, se remonta a finales del siglo XIX con la aparición de las fincas cafetaleras (Ayala-Carillo y Cárcamo-Toalá, 2012). En aquella época se necesitó de la mano de obra guatemalteca para la producción del café y el mantenimiento de las fincas. Sin embargo, el asentamiento de guatemaltecos en México ocurrió a baja escala, debido a la alta circularidad de la migración, determinada por los ciclos agrícolas.

Fue hasta hace cuatro décadas cuando se inició el éxodo de guatemaltecos a México. De acuerdo con Kauffer (2000), como resultado de la guerra civil en Guatemala, a principios de los años ochenta, tanto pequeños grupos como comunidades completas de guatemaltecos, en gran parte conformadas por indígenas, lograron cruzar la frontera mexicana en busca de seguridad. Algunos se integraron a rancherías mexicanas o comunidades indígenas fronterizas y otros formaron campamentos de refugiados en algunos municipios de acogida en Chiapas, donde recibieron asistencia institucional como Ocosingo, Las Margaritas, La Independencia, La Trinitaria, Frontera Comalapa y Amatenango de la Frontera (González, 2015; Kauffer, 2005; Ruiz, 2018).

Durante 1984 el gobierno mexicano decidió reubicar a una parte de los refugiados guatemaltecos en Campeche y Quintana Roo, ya que la localización fronteriza de los campamentos atrajo al ejército guatemalteco a territorio mexicano, lo cual representó un peligro de seguridad nacional (Ruiz, 2018). Por esta razón, y no siempre de forma voluntaria, se reubicaron miles de guatemaltecos en otras entidades de México, con el soporte de la Comisión Mexicana de Ayuda a Refugiados (COMAR) y el financiamiento de la Comunidad Económica Europea (CEE) para su integración. De los 45000 refugiados que había entonces en Chiapas, la mitad llegó a aquellas entidades, otros se quedaron en los asentamientos chiapanecos, o bien se ocultaron en la selva de la zona de Marqués de Comillas o regresaron a Guatemala (Kauffer, 2000).

Como apunta Kauffer (2000), desde 1987, con el establecimiento en Guatemala de la Oficina del Procurador de Derechos Humanos y el fin de la guerra, el gobierno mexicano impulsó también el retorno de los guatemaltecos. Sin embargo, la inestabilidad política y socioeconómica continuaba en este país, y no fue hasta 1996 cuando se promovieron los retornos de forma organizada, tras la firma de los acuerdos de paz, que contemplaban brindar garantías para la repatriación (Ruiz, 2011).

No obstante, para esta época, los guatemaltecos, con más de una década de asentamiento, estaban en camino a la integración en México y no todos deseaban 
regresar a su país. De hecho, algunos tenían cónyuges mexicanos y sus hijos ya eran mexicanos por nacimiento, además los padres de familia expresaban su interés en quedarse por las oportunidades que podrían encontrar para sus hijos en México (Ruiz, 2011). Asimismo, después de los múltiples desplazamientos a los que fueron sujetos, ya estaban finalmente asentados y el retorno implicaba iniciar su incorporación en un nuevo destino (Kauffer, 2005). Incluso, para algunos regresar a Guatemala resultaba complicado porque habían perdido sus actas y registros de nacimiento a consecuencia del conflicto armado (Ruiz, 2018).

Cabe señalar que la integración de los guatemaltecos en México no ha sido fácil y ha sido un proceso desigual (Chan y García, 2018; Kauffer, 2000; 2005; Ruiz, 2018). Este ha dependido de la estructura de oportunidades del lugar de asentamiento, los apoyos económicos o de tierras obtenidos para ello, la clase social, el nivel de organización de las comunidades y la rapidez con que se ha llevado a cabo el proceso de documentación, ya sea para conseguir documentos migratorios de no inmigrante o de inmigrante, o para naturalizarse como mexicanos. Aquellos residentes con documentación han tenido mayores oportunidades para desplazarse a diferentes áreas en busca de oportunidades laborales y aquellos con mayor organización han logrado gestionar la dotación de tierras y servicios públicos. Por ejemplo, en Chiapas fue más difícil el acceso a tierras, vivienda y servicios en comparación con los otros estados de México donde los refugiados fueron reubicados y lograron mayor organización comunitaria. Además, el proceso de naturalización en Chiapas fue más lento e ineficiente y el alzamiento del movimiento zapatista en 1994 complicó el proceso de integración (González, 2015).

Para 1999, según datos de la comar (citado por Kauffer, 2000), había alrededor de 12350 guatemaltecos en Chiapas en vías de integración y en Campeche y Quintana Roo, 8634 y 2900 personas respectivamente, contando a sus descendientes mexicanos. Para este año aún las instituciones nacionales e internacionales apoyaban la integración de los refugiados en Chiapas y su supervivencia era un desafío. No obstante, en contraste al conteo oficial, la diócesis de San Cristóbal llegó a contar 100000 refugiados, a los cuales apoyó con asistencia de distinta índole y se tiene evidencia que no todos lograron tener el estatus de refugiado debido a que enfrentaron dificultades en el proceso de regularización y altos niveles de pobreza (Ruiz, 2018).

Es necesario notar que la migración de guatemaltecos a México no solo se debe a la guerra civil en Guatemala. Desde los años noventa, debido al modelo económico neoliberal adoptado por los gobiernos de la región, se registró un mayor desequilibrio, desigualdad e inestabilidad económica, que llevó a la exclusión de grandes contingentes de trabajadores (Castillo y Toussaint, 2015). En especial, comunidades de mames, chujes, cakchiqueles, kanjobales, jacaltecas y mochós sufrieron durante los últimos diez años cambios en sus dinámicas sociales, debido al impacto de las políticas agrícolas neoliberales en la economía campesina (Hernández, 2012). Así, esta crisis agrícola ha llevado a la emigración sostenida de guatemaltecos a México, en especial de estos pueblos indígenas, no solo para laborar en el campo, sino también en otros empleos como el trabajo doméstico, la venta ambulante, la albañilería, la construcción, la recolección de basura y otros oficios del sector informal.

Otro factor que propició la salida de los guatemaltecos a México fue el clima de violencia social en la etapa del postconflicto armado en Guatemala (Duarte y Coello, 
2007). Si bien los acuerdos de paz se firmaron en 1996, la violencia aumentó y se expandió, pues sectores del crimen organizado dominaron en parte el escenario económico. La violencia en este país se vinculó a los conflictos entre los grupos paramilitares, exparamilitares y narcotraficantes, y esto propició nuevas oleadas de ciudadanos guatemaltecos hacia el territorio mexicano.

Por último, es importante señalar el impacto que han tenido los desastres naturales sobre los flujos migratorios de Guatemala a México. Los huracanes Mitch en 1998 y Stan en 2005 provocaron fuertes daños en el sector productivo, la infraestructura y la vivienda, impulsando también la emigración internacional de los guatemaltecos (Duarte y Coello, 2007; Hernández, 2012). Estos huracanes agudizaron la crisis agrícola, misma que ya afectaba a los productores de la región desde hace dos décadas, acelerando la migración — por ejemplo— de hombres y mujeres indígenas hacia las ciudades turísticas del Caribe mexicano (Hernández, 2012).

Por otra parte, cabe aclarar, que además de los guatemaltecos asentados en territorio mexicano, están aquellos que tienen empleos transfronterizos y no tienen su residencia habitual en México. El empleo transfronterizo de cruce diario, semanal o por temporadas también es común en esta frontera. El cruce e inserción laboral se ha tratado de regular a través de los permisos temporales de trabajo. Así, “[...] con la Ley de Migración de 2011, la movilidad laboral transfronteriza de guatemaltecos a México es permitida ... en las entidades del sur de México, independientemente del departamento de procedencia, obteniendo una Tarjeta de Visitante Trabajador Fronterizo (TVTF)" (Nájera, 2017, p. 122). Este permiso debe renovarse anualmente y permite la inserción laboral documentada. Autoriza a empleadores mexicanos a la contratación de mano de obra guatemalteca como trabajadores temporales en los estados de Chiapas, Campeche, Quintana Roo y Tabasco. Son contratados principalmente para trabajar en los campos agrícolas, pero también en el empleo doméstico y en una amplia gama de oficios.

Los guatemaltecos también se encuentran de forma temporal en México por otras razones. Existe igualmente la posibilidad de adquirir la Tarjeta de Visitante Regional (TVR), la cual permite la internación de personas procedentes de Belice y Guatemala — que residen en sus países- y que visitan las poblaciones fronterizas para realizar estancias cortas, de días u horas, para realizar compras, visitas familiares o acceso a servicios médicos. Por otra parte, existe una intensa dinámica fronteriza de guatemaltecos que cruzan la frontera cotidianamente con distintos fines, aún sin contar con ningún documento migratorio; por ejemplo, por senderos conocidos que permiten esquivar el pago de cruce y la inspección fronteriza (Ruiz, 2018). Y se presenta además, un flujo constante de guatemaltecos y de otros países centroamericanos en tránsito a Estados Unidos (Rivera, 2014, pp. 12-17).

En síntesis, las poblaciones de México y Guatemala han experimentado una fuerte interacción a través del tiempo. La contigüidad geográfica y la historia compartida han permitido el desarrollo de lazos culturales y redes sociales, así como la movilidad a través de la frontera por décadas. El establecimiento permanente de la población de origen guatemalteco en México, sobre todo en los estados fronterizos, ha estado influida por múltiples determinantes como los conflictos armados, la violencia, los desastres naturales y las crisis económicas, los cuales han motivado a esta población a migrar en búsqueda de seguridad, trabajo y mejores opciones de vida. 


\section{Metodología}

\section{Fuente de información y área geográfica de análisis}

La principal fuente de datos fue la muestra de 20\% de la Encuesta Intercensal 2015 (Inegi, 2015). Este estudio toma como unidad de análisis a los hogares censales, es decir, compuestos por aquellos miembros que residen habitualmente en la misma vivienda (Inegi, 2019). Los hogares guatemaltecos se definieron en el estudio como aquellos cuyo jefe(a) y su cónyuge eran nacidos en Guatemala. Con esta estrategia de análisis incluimos $86 \%$ del total de hogares con algún miembro nacido en Guatemala. En el resto de los hogares con algún miembro guatemalteco, $60 \%$ de los guatemaltecos no tenían relación de parentesco con el jefe o no lo especificaban, pudiéndose tratar de trabajadores temporales en territorio mexicano. Cuando se especificaba el parentesco, eran comúnmente nuera o primo, y se encontraban en hogares dirigidos por mexicanos por nacimiento.

Con la idea de poder comparar los perfiles sociodemográficos con los de aquellos que residen en los lugares donde se concentran los guatemaltecos, el estudio se centró en los municipios de las entidades del sur de México donde al menos 1\% de los hogares eran de origen guatemalteco en 2015. ${ }^{2}$ Si bien los guatemaltecos se han dispersado o migrado hacia otros municipios, aún se observa una concentración importante. En estos municipios residían $92 \%$ de los hogares guatemaltecos en 2000 y $77 \%$ en 2015 (Inegi, 2001; 2015). Esto no quiere decir que no exista presencia guatemalteca en otros municipios de las entidades de la frontera Sur de México, solo que el peso relativo de las poblaciones es bajo.

Los municipios de concentración guatemalteca se muestran en la Figura 1 como aquellos de la segunda categoría y subsecuentes (en colores más oscuros, con porcentajes de guatemaltecos superiores al 1\%). La gran mayoría se ubican cerca o en la frontera de México con Guatemala, solo tres municipios están fuera de esta zona, los cuales fueron lugares de asentamiento de refugiados en los años ochenta del siglo xx. Por ejemplo, Bacalar, en Quintana Roo, donde viven comunidades de refugiados guatemaltecos hablantes de lengua indígena (HLI) que han desarrollado la agricultura y su comercialización en ciudades aledañas como Chetumal y Cancún (Chan y García, 2018). El municipio con mayor porcentaje de guatemaltecos en las entidades de la frontera sur fue Suchiate, seguido por Mazatán, Benemérito de las Américas, Bacalar, Metapa, La Trinitaria, Frontera Hidalgo, Frontera Comalapa y Maravilla Tenejapa, los cuales se ubican en las últimas dos categorías de la Figura 1 (con $4.19 \%$ de hogares guatemaltecos o más).

\footnotetext{
${ }^{2}$ Los 26 municipios que tenían en 2015 más de $1 \%$ de hogares guatemaltecos fueron: en Campeche, Campeche y Champotón; en Quintana Roo, Bacalar; y en Chiapas, Acapetahua, Amatenango de la Frontera, Ángel Albino Corzo, Bella Vista, Cacahoatán, Frontera Comalapa, Frontera Hidalgo, Huehuetán, Huixtla, La Independencia, Mazapa de Madero, Mazatán, Metapa, Motozintla, Suchiate, Tapachula, La Trinitaria, Tuxtla Chico, Tuzantán, Unión Juárez, Benemérito de las Américas, Maravilla Tenejapa y Marqués de Comillas.
} 
Figura 1: Porcentaje de hogares guatemaltecos en municipios de entidades de frontera sur de México, 2015

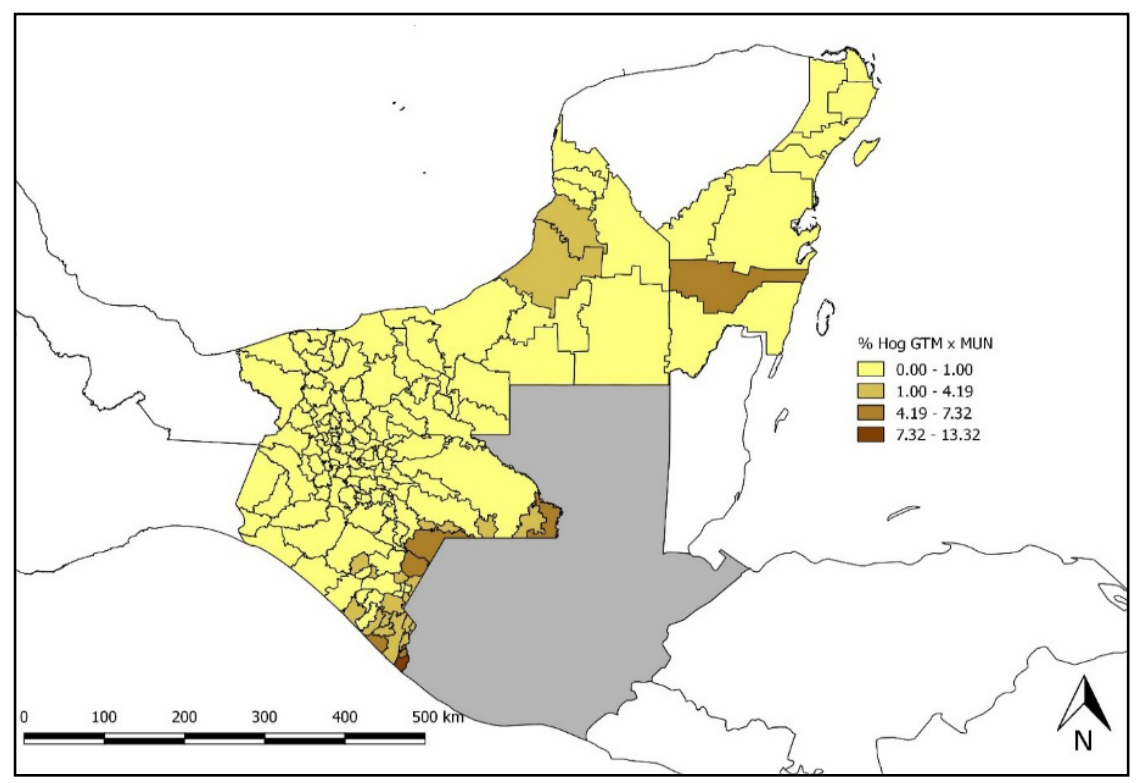

Fuente: Elaboración propia con base en Inegi, 2015.

\section{Variables y análisis estadístico}

Con el fin de conocer cómo se han integrado socioeconómicamente los hogares guatemaltecos y, en particular, los perfiles específicos de los que son indígenas, se creó una variable dependiente que definimos tipo de hogar, la cual combina el nacimiento en Guatemala del jefe(a) o su cónyuge con el habla de lengua indígena de alguno de estos miembros del hogar. Así, la variable dependiente tipo de hogar incluyó cuatro categorías: hogares mexicanos no HLI, hogares mexicanos HLI, hogares guatemaltecos no HLI y hogares guatemaltecos HLI. Se prefirió este criterio que el uso de la autoadscripción étnica con base en la cultura, porque se ha probado que esta variable sobreestima el volumen de la población indígena, debido a que los mexicanos pudieran sentir que deben considerarse indígenas por ser México poseedor de una cultura mestiza con un fuerte componente indígena (Vázquez y Félix, 2015).

Para definir el perfil de los hogares guatemaltecos, se usó un conjunto de variables que caracterizan tanto la composición de los hogares como su inserción socioeconómica. Entre las variables ligadas a la composición del hogar se evaluaron: la estructura del hogar censal (nuclear, ampliada, compuesta, unipersonal u otra), ${ }^{3}$ el

${ }^{3}$ Se toma como base la definición censal del tipo de estructura del hogar (Inegi, 2019). Nuclear se refiere a un hogar familiar conformado por el jefe(a) y cónyuge; el jefe(a) e hijos(as); o el jefe(a), cónyuge e hijos(as). El hogar ampliado incluye parientes coresidentes además de los anteriores. El hogar compuesto añade la presencia de no parientes en el hogar. Los hogares unipersonales son hogares no familiares, integrados por una sola persona. En otros quedaron clasificados los hogares de coresidentes sin vínculos de parentesco con el jefe de hogar. 
promedio de residentes y de guatemaltecos, la edad y el sexo del jefe, si la pareja del jefe reside en el hogar, el promedio de hijos residentes y nacidos vivos de la pareja o jefa y el porcentaje de miembros guatemaltecos naturalizados mexicanos.

Tabla 1: Definición de variables socioeconómicas

\begin{tabular}{|c|c|c|c|}
\hline Variable & Tipo & Definición & Categorías o rangos \\
\hline Migración reciente & Categórica & $\begin{array}{l}\text { Jefe residía en otro país hace } \\
5 \text { años }\end{array}$ & 0 No, 1 Sí \\
\hline Trabaja* & Categórica & Trabajó la semana pasada & 0 No, 1 Sí \\
\hline & & & 1 Sector primario \\
\hline Sector de actividad* & Categórica & Sector de actividad económica & 2 Sector secundario \\
\hline & & & 3 Sector terciario \\
\hline Hijo menor no estudia & Categórica & $\begin{array}{l}\text { Al menos uno de los hijos } \\
\text { menores de } 18 \text { años no estudia }\end{array}$ & $\begin{array}{l}0 \text { No, todos estudian } \\
1 \text { Sí, no estudia }\end{array}$ \\
\hline$\%$ trabajadores & Numérica & $\begin{array}{l}\text { Porcentaje de trabajadores } \\
\text { respecto a miembros en hogar }\end{array}$ & 0 a $100 \%$ \\
\hline Localidad rural & Categórica & $\begin{array}{l}\text { Localidad con }<15000 \text { habi- } \\
\text { tantes }\end{array}$ & 0 Urbana, 1 Rural \\
\hline Tenencia de vivienda & Categórica & $\begin{array}{l}\text { Algún miembro del hogar es } \\
\text { dueño de la vivienda }\end{array}$ & $\begin{array}{l}0 \text { No, rentada } \\
1 \text { Sí, propia } \\
2 \text { No, otra }\end{array}$ \\
\hline Grado de hacinamiento & Numérica & $\begin{array}{l}\text { Razón de personas por cuarto } \\
\text { para dormir }\end{array}$ & 0.07 a 16 personas \\
\hline Agua entubada & Categórica & $\begin{array}{c}\text { Agua entubada dentro de la } \\
\text { vivienda }\end{array}$ & 0 No, 1 Sí \\
\hline Ingresos & Numérica & Ingresos por trabajo per cápita & 0 a 499997 \\
\hline Seguridad médica & Categórica & $\begin{array}{l}\text { Tipo de seguridad médica de } \\
\text { los miembros del hogar }\end{array}$ & $\begin{array}{l}0 \text { Sin seguridad } \\
1 \text { Solo Seguro Popular } \\
2 \text { Solo IMSS o ISSTE } \\
3 \text { Ambos }\end{array}$ \\
\hline Bienes & Numérica & $\begin{array}{l}\text { Número de bienes (refrigera- } \\
\text { dor, lavadora, televisión (TV), } \\
\text { teléfono fijo, celular, auto, } \\
\text { computadora, internet y servi- } \\
\text { cio TV de paga). }\end{array}$ & 0 a 9 bienes \\
\hline Apoyo gobierno & Categórica & $\begin{array}{l}\text { Algún miembro del hogar } \\
\text { recibe apoyo del gobierno }\end{array}$ & 0 No, 1 Sí \\
\hline Remesas & Categórica & $\begin{array}{l}\text { Algún miembro del hogar } \\
\text { recibe remesas }\end{array}$ & 0 No, 1 Sí \\
\hline
\end{tabular}

Fuente: Elaboración propia.

*Nota: Fueron estimadas para el jefe, la pareja del jefe y los hijos. Se consideró si trabajaba al menos uno de los hijos, dando prioridad a registrar las actividades agropecuarias de estos. 
Las variables relativas a los perfiles socioeconómicos de los hogares se subdividieron en las que se refieren al jefe, a la pareja, a los hijos, y por último, al hogar en su conjunto. Dada la complejidad de algunas de estas variables, su definición se detalla en la Tabla 1. Entre las variables del jefe, se ubicó la inmigración reciente de otro país, si trabaja y el sector de actividad económica. Entre las variables de la pareja, se incluyó su participación económica y el sector de actividad. Entre las variables de los hijos residentes, se identificó también su participación económica, el sector de actividad y si alguno de los hijos menores no asiste a la escuela. Finalmente, entre las variables del hogar se computó la localización en áreas rurales, el porcentaje de trabajadores en el hogar, el acceso a seguridad médica, la recepción de apoyo de gobierno y de remesas, el grado de hacinamiento, la tenencia de la vivienda, el acceso a agua entubada, el promedio de ingresos por trabajo per cápita y el promedio de bienes duraderos.

$\mathrm{El}$ análisis se basó en estadística descriptiva (medias y frecuencias) y un modelo de regresión logística multinomial que consideró como variable dependiente el tipo de hogar. Para la estimación del modelo, se hicieron pruebas de asociaciones bivariadas de cada una de las variables con la variable dependiente, así como matrices de correlaciones entre variables independientes. Aquellas variables que manifestaron una alta correlación entre sí fueron evaluadas de acuerdo a su relación con la variable dependiente y solo una de ellas fue introducida en los modelos finales. Tal es el caso, por ejemplo, de variables como: los bienes y los ingresos; el tipo de actividad económica de los jefes y la de los hijos; la estructura del hogar y la edad del jefe; así como los números de hijos residentes y de hijos nacidos vivos. Finalmente, se determinó el modelo con el conjunto de variables que proporcionaron una mejor bondad de ajuste, de acuerdo con pruebas de razones del logaritmo de verosimilitud.

\section{Resultados}

\section{La configuración y la caracterización de los hogares guatemaltecos en México según habla de lengua indígena}

En los municipios seleccionados del sur de México, 3.4\% de los hogares son guatemaltecos. Del total de hogares guatemaltecos, $31 \%$ registró habla de lengua indígena, en comparación con solo 7.2\% de los hogares mexicanos. Si bien las zonas "Frontera Sur" y "Selva Lacandona", donde se encuentra la mayoría de los municipios analizados, tienen presencia indígena importante, no son las de mayor concentración indígena mexicana como lo serían los Altos de Chiapas y otros municipios de la región maya en la Península de Yucatán (Comisión Nacional para el Desarrollo de los Pueblos Indígenas y Programa de las Naciones Unidas para el Desarrollo, 2006). Lo anterior debido a que los guatemaltecos ocuparon territorios de la frontera poco poblados, donde se les asignaron o compraron terrenos o tenían parientes con quienes residir (Kauffer, 2005). Las tres principales lenguas indígenas de los guatemaltecos fueron el Mame, el Kanjobal y el Akateko, pero también destacan lenguas como el Chuj, quiché y K'ekchi (ver Figura 2). Cabe señalar que las etiquetas de las lenguas se anotaron tal como se reportan en la fuente de información y que el perfil lingüístico de estos inmigrantes coincide con el encontrado en el año 2000 (cálculos propios a partir del análisis del Censo de Población y Vivienda, Inegi 2001). 
Figura 2: Principales lenguas indígenas de los guatemaltecos en los municipios seleccionados de las entidades de la frontera sur de México, 2015

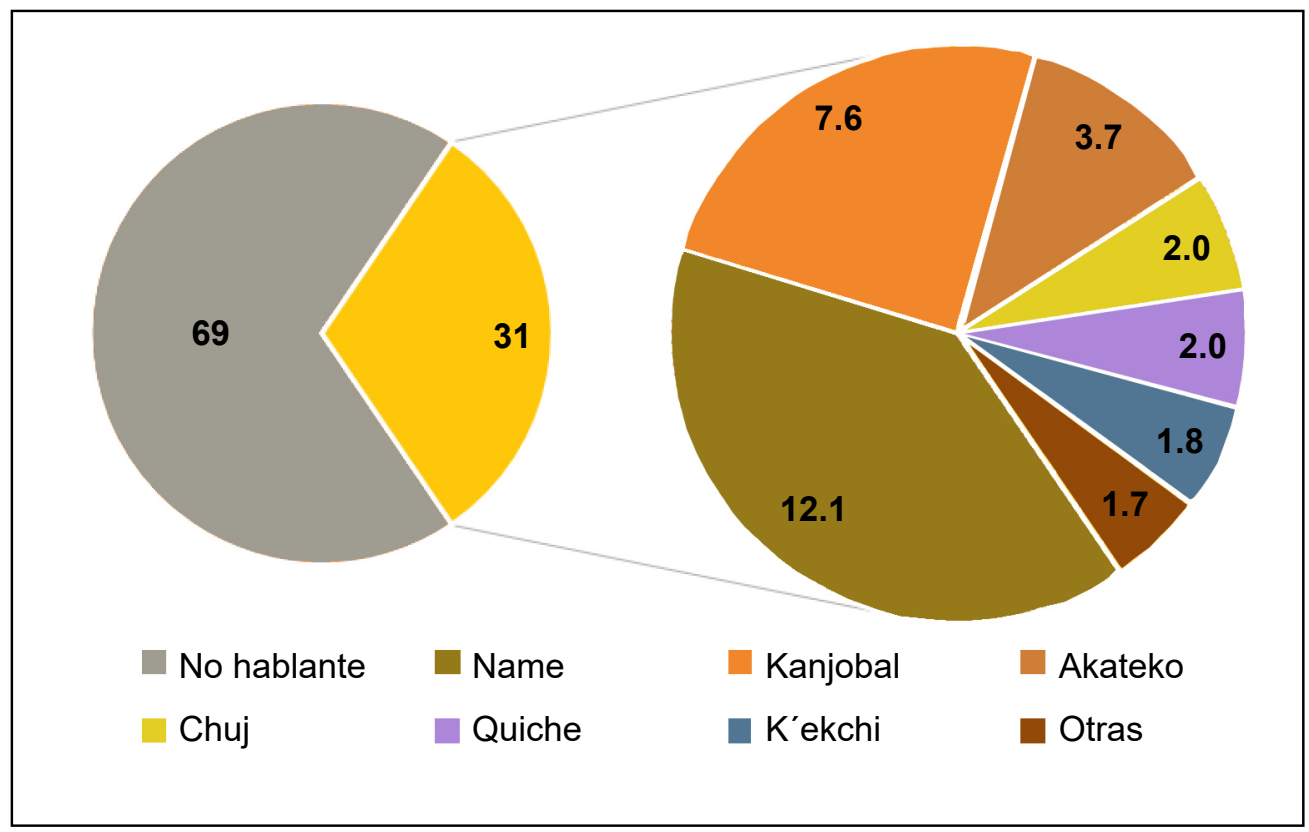

Fuente: Elaboración propia con base en Inegi (2015).

En cuanto a la composición de los hogares guatemaltecos, en primer lugar, es notorio que estos tienen más miembros que los mexicanos (Tabla 2). Entre los hablantes de lengua indígena (HLI), el promedio de residentes en los hogares guatemaltecos es de 5.2 personas, en comparación con 4.3 personas en los mexicanos. En cambio, entre los no HLI, el número promedio de residentes en los hogares guatemaltecos es de 4.4 personas, siendo menor el diferencial con los mexicanos, ya que estos últimos presentan en promedio 3.9 personas. En total, estos promedios equivalen a 60000 personas residiendo en hogares guatemaltecos tan solo en estos 26 municipios de la frontera sur de México.

Es importante señalar que en los hogares guatemaltecos solo alrededor de dos miembros son nacidos en Guatemala, lo cual nos indica que la mayoría de los hijos ya fueron nacidos en México. Otra variable que nos ayuda a entender el nivel de integración política de estas poblaciones es el porcentaje de ciudadanos mexicanos respecto al total de miembros guatemaltecos. Se observa que en los hogares HLI es donde ha sido más común la naturalización. En promedio, casi $70 \%$ de los miembros nacidos en Guatemala en hogares indígenas son ciudadanos mexicanos, en comparación con solo $20 \%$ de los miembros en hogares no HLI. Los guatemaltecos HLI tienen una historia compartida con los pueblos mayas originarios de la frontera, lo cual podría favorecer los matrimonios entre guatemaltecos y mexicanos del mismo grupo lingüístico (Lerma, 2016; Rodríguez y Caballeros, 2020). Además, se ha documentado la existencia de un alto porcentaje de indígenas entre los refugiados guatemaltecos de los años ochenta (Kauffer, 2005), los cuales estuvieron expuestos a diversas campañas de naturalización (González, 2015; Ruiz, 2018). 
$\mathrm{Al}$ analizar el promedio de hijos residentes en el hogar (Tabla 2), se observa que entre los guatemaltecos hay un mayor número de hijos residentes, sobre todo entre los HLI (2.6 hijos versus 1.8 hijos de los mexicanos). Entre los no HLI, este mayor número de hijos también se identifica en los guatemaltecos, a comparación de los mexicanos (2 hijos versus 1.6 hijos). Esto podría estar ligado a diferenciales en la fecundidad, a distintos momentos del ciclo de vida del hogar y a la tendencia de los hijos unidos de coresidir con los padres.

\section{Tabla 2: Características demográficas de hogares por país de nacimiento de acuerdo con la lengua indígena del jefe(a) o su cónyuge. Municipios con $1 \%$ o más de hogares guatemaltecos. Frontera Sur de México, 2015}

\begin{tabular}{|c|c|c|c|c|}
\hline \multirow[t]{2}{*}{ Variables } & \multicolumn{2}{|c|}{ Guatemaltecos } & \multicolumn{2}{|c|}{ Mexicanos } \\
\hline & HLI* & No HLI* & HLI* & No HLI* \\
\hline Tamaño de muestra ( $\mathrm{n}$ hogares) & 1918 & 2537 & 8050 & 75783 \\
\hline Número de hogares & 4012 & 8938 & 26708 & 342314 \\
\hline PORCENTAJE RENGLÓN & $31.0 \%$ & $69.0 \%$ & $7.2 \%$ & $92.8 \%$ \\
\hline Promedio de residentes totales & 5.2 & 4.4 & 4.3 & 3.9 \\
\hline Promedio de guatemaltecos & 2.1 & 1.9 & - & - \\
\hline Nacionalidad mexicana de guatemaltecos & $69.4 \%$ & $20.2 \%$ & - & - \\
\hline Edad promedio del jefe & 46.6 & 39.7 & 50.5 & 47.6 \\
\hline Promedio de hijos residentes en el hogar & 2.6 & 2.0 & 1.8 & 1.6 \\
\hline Promedio hijos nacidos vivos (de pareja o jefa) & 5.3 & 3.5 & 4.3 & 3.4 \\
\hline Jefe es mujer & $16.9 \%$ & $21.1 \%$ & $20.7 \%$ & $30.1 \%$ \\
\hline Sin pareja residente en el hogar & $27.5 \%$ & $23.5 \%$ & $23.9 \%$ & $34.0 \%$ \\
\hline
\end{tabular}

Fuente: Estimaciones propias con base en Encuesta Intercensal 2015 (Inegi, 2015).

* Nota: $\mathrm{HLI}=$ Hablantes de lengua indígena.

Respecto al primer punto, se incluye en la Tabla 2 el promedio de los hijos nacidos vivos de la pareja del jefe o jefa. Se observa que entre los HLI, el promedio de hijos es mayor en los guatemaltecos ( 5.3 hijos) en comparación con los mexicanos (4.3 hijos). En contraste, no hay diferencias en el número de hijos de los no HLI de ambos países. En cuanto al segundo punto, se distingue que la edad promedio del jefe o la jefa es menor entre los guatemaltecos, sugiriendo también una etapa más temprana del ciclo del hogar.

Además, como puede notarse en la Figura 3, los guatemaltecos HLI son ligeramente más propensos a residir en hogares extensos que los mexicanos HLI, 33\% versus $31 \%$, cifras que son superiores a los de los no HLI. Esta tendencia puede asociarse tanto a los usos y costumbres de las comunidades indígenas (Robichaux, 2002) como a la necesidad de residir con la familia extensa como una estrategia de supervivencia ante las dificultades económicas (Jelin, 1991). Llama la atención también la mayor 
concentración de los guatemaltecos no HLI en hogares nucleares, respecto a los demás tipos de hogar.

Figura 3: Estructura de los hogares por origen guatemalteco y habla de lengua indígena. Municipios seleccionados en la frontera sur de México, 2015

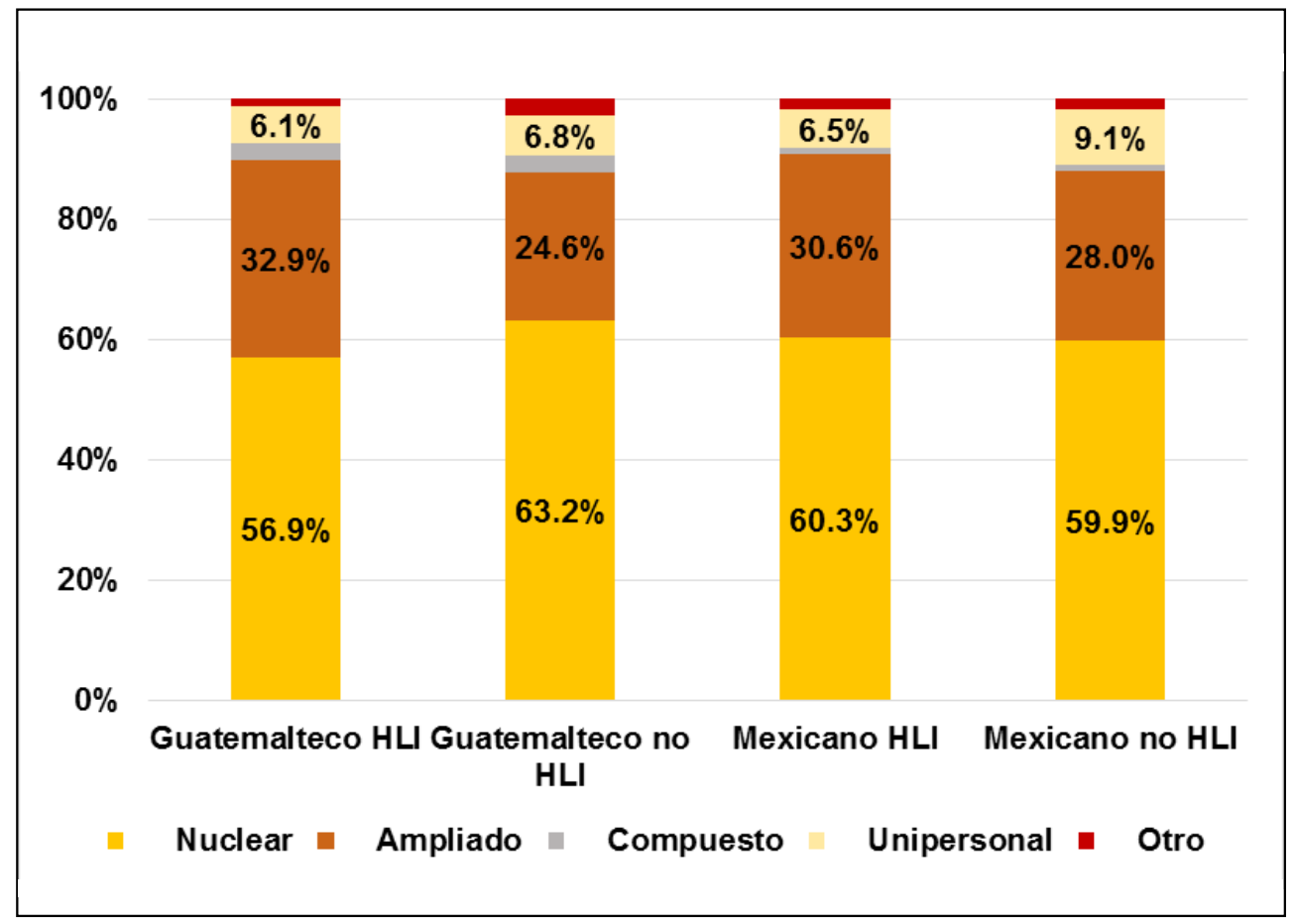

Fuente: Elaboración propia con base en Inegi (2015).

Otras características importantes de la configuración de los hogares guatemaltecos es la baja jefatura femenina (Tabla 2). Entre los HLI, solo $17 \%$ de los hogares guatemaltecos presenta jefatura femenina, en comparación con $21 \%$ de los hogares mexicanos. Esto sucede a pesar de que la coresidencia con la pareja es menor entre los indígenas guatemaltecos que entre los indígenas mexicanos, lo cual sugiere que en caso de ausencia del jefe, un hijo varón suele quedar a cargo de los hogares, rasgo común en familias patrilocales mesoamericanas (Robichaux, 2002). Por último, llama la atención que entre los hogares no HLI, la brecha es mucho mayor, solo $21 \%$ de los hogares guatemaltecos registran jefatura femenina, en contraste con $30 \%$ de los mexicanos.

En cuanto a las variables socioeconómicas del jefe, solo cerca de $7 \%$ de los jefes guatemaltecos HLI y $9 \%$ de los no HLI registraron haber inmigrado de otro país a estos municipios seleccionados en los últimos cinco años (Tabla 3). Es decir, aunque se siguió registrando el ingreso de guatemaltecos a la zona, en 2015 la gran mayoría de los jefes tenían cinco o más años en México. Esto coincide con la larga historia de asentamientos guatemaltecos en este país, que se multiplicaron con los conflictos políticos de los años ochenta, las crisis económicas de los años noventa y las catástrofes ambientales de la primera década del siglo xxi. 
Tabla 3: Características socioeconómicas de hogares por origen guatemalteco del jefe(a) o esposo(a) de acuerdo con la lengua indígena. Municipios con $1 \%$ o más de hogares guatemaltecos. Frontera sur, México, 2015

\begin{tabular}{|c|c|c|c|c|}
\hline \multirow{2}{*}{ Variables } & \multicolumn{2}{|c|}{ Guatemaltecos } & \multicolumn{2}{|c|}{ Mexicanos } \\
\hline & HLI* & No HLI* & HLI* & No HLI* \\
\hline Tamaño de muestra (n) & 1918 & 2537 & 8050 & 75783 \\
\hline \multicolumn{5}{|l|}{ Del jefe } \\
\hline Migración internacional reciente & $6.8 \%$ & $9.0 \%$ & $0.3 \%$ & $0.6 \%$ \\
\hline Trabaja & $76.2 \%$ & $82.4 \%$ & $73.4 \%$ & $71.4 \%$ \\
\hline \multicolumn{5}{|l|}{ Sector de actividad } \\
\hline Primario & $71.8 \%$ & $41.1 \%$ & $50.2 \%$ & $31.0 \%$ \\
\hline Secundario & $9.3 \%$ & $17.5 \%$ & $14.2 \%$ & $15.6 \%$ \\
\hline Terciario & $18.9 \%$ & $41.4 \%$ & $35.6 \%$ & $53.4 \%$ \\
\hline \multicolumn{5}{|l|}{ De la pareja (del jefe(a)) } \\
\hline Trabaja & $13.1 \%$ & $27.2 \%$ & $25.6 \%$ & $29.0 \%$ \\
\hline Principal sector en el que trabajan & $\begin{array}{l}60.4 \% \text { ter- } \\
\text { ciario }\end{array}$ & $64.3 \%$ terciario & $69.8 \%$ terciario & $\begin{array}{l}79.4 \% \text { ter } \\
\text { ciario }\end{array}$ \\
\hline \multicolumn{5}{|l|}{ De los hijos } \\
\hline Al menos un hijo residente trabaja & $45.4 \%$ & $28.0 \%$ & $41.8 \%$ & $33.8 \%$ \\
\hline Principal sector de actividad laboral & $\begin{array}{c}62.4 \% \text { pri- } \\
\text { mario }\end{array}$ & $46.2 \%$ terciario & $47.0 \%$ terciario & $\begin{array}{l}59.1 \% \text { ter } \\
\quad \text { ciario }\end{array}$ \\
\hline Hijo menor no estudia & $26.6 \%$ & $22.2 \%$ & $10.0 \%$ & $6.8 \%$ \\
\hline \multicolumn{5}{|l|}{ Del hogar } \\
\hline$\%$ de trabajadores entre residentes & $36.3 \%$ & $41.5 \%$ & $39.4 \%$ & $39.8 \%$ \\
\hline Localidad rural & $90.2 \%$ & $68.7 \%$ & $64.7 \%$ & $54.2 \%$ \\
\hline Tenencia de vivienda & $77.4 \%$ & $37.8 \%$ & $85.3 \%$ & $74.8 \%$ \\
\hline Grado de hacinamiento & 3.3 & 3.3 & 2.7 & 2.4 \\
\hline Con agua entubada dentro de la vivienda & $26.9 \%$ & $43.8 \%$ & $45.7 \%$ & $60.7 \%$ \\
\hline Ingresos por trabajo per capita & $\$ 852.9$ & $\$ 1702.9$ & $\$ 1579.3$ & $\$ 2096.6$ \\
\hline \multicolumn{5}{|l|}{ Seguridad médica } \\
\hline Sin seguridad médica & $23.7 \%$ & $44.4 \%$ & $5.4 \%$ & $9.9 \%$ \\
\hline Solo con Seguro Popular & $70.8 \%$ & $39.9 \%$ & $56.3 \%$ & $49.1 \%$ \\
\hline Solo con IMSS o ISSTE & $3.1 \%$ & $8.9 \%$ & $22.2 \%$ & $27.5 \%$ \\
\hline Con ambos & $2.4 \%$ & $6.8 \%$ & $16.1 \%$ & $13.5 \%$ \\
\hline Promedio de bienes duraderos & 2.8 & 2.9 & 4.1 & 4.3 \\
\hline Algún miembro recibe apoyo de gobierno & $67.6 \%$ & $29.5 \%$ & $56.8 \%$ & $44.1 \%$ \\
\hline Algún miembro recibe remesas & $5.5 \%$ & $5.2 \%$ & $2.5 \%$ & $3.5 \%$ \\
\hline
\end{tabular}

Fuente: Estimaciones propias con base en Encuesta Intercensal 2015 (Inegi, 2015).

* Nota: $\mathrm{HLI}=$ Hablantes de lengua indígena. 
Unas de las principales características de los guatemaltecos son su alta participación laboral y concentración en actividades agropecuarias (Tabla 3). Entre los jefes guatemaltecos, trabajan $76 \%$ de los HLI y $82 \%$ de los no HLI, cifras más altas que entre los mexicanos de ambos segmentos poblacionales. Además, existen diferencias por habla de lengua indígena en el sector predominante de inserción laboral. Los HLI de cualquier país se concentran en el sector primario, especialmente aquellos de origen guatemalteco. En cambio, los guatemaltecos no HLi han encontrado oportunidades más diversificadas, pues se ubican en igual proporción en el sector primario y el terciario, aunque en términos relativos registran mayor participación en la agricultura que los mexicanos no HLI.

Respecto a las parejas de los jefes o jefas, se encuentra que las parejas guatemaltecas HLI tienden a trabajar mucho menos que las mexicanas HLI, pero cuando lo hacen, se insertan principalmente en el sector terciario, al igual que las mexicanas (Tabla 3). Así, la participación económica extra-doméstica de las parejas guatemaltecas HLI es solo $13 \%$, en comparación con $26 \%$ de las mexicanas HLI. En cambio, entre las no HLI las diferencias en este indicador por país de nacimiento son muy pequeñas (27.2\% en las guatemaltecas y $29 \%$ en las mexicanas). Al respecto, Chan y García (2018) ilustran cómo las mujeres guatemaltecas tienen una aportación importante en el comercio de verduras y frutas que se cultivan en Quintana Roo. La participación de las guatemaltecas en el comercio también se ha documentado ampliamente en Chiapas (Meza, 2015).

$\mathrm{Al}$ evaluar la participación económica de los hijos guatemaltecos, se observa que esta variable para los hijos en los hogares HLI es más alto (Tabla 3). En $45 \%$ de los hogares guatemaltecos HLI al menos un hijo trabaja, en comparación con $42 \%$ de los hogares indígenas mexicanos. Esto no sucede entre los no HLI, donde los hijos guatemaltecos exhiben una más baja inserción laboral que los mexicanos, lo cual puede deberse a que estos hogares están en una etapa más temprana del ciclo de vida del hogar. Además, el principal sector de actividad de los hijos de guatemaltecos HLI es el primario, a diferencia de los hijos de los demás tipos de hogares quienes se ubican primordialmente en el sector terciario.

Una característica común de los hijos en hogares guatemaltecos, tanto HLI como no HLI, es que estudian menos que aquellos en hogares mexicanos (Tabla 3). En los hijos menores de 18 años de los hogares guatemaltecos HLI la inasistencia escolar llega a ser $27 \%$, y $22 \%$ en los no HLI, mientras que estas cifras apenas alcanzan $10 \%$ entre los mexicanos. Como han observado diversos estudios, los niños y niñas guatemaltecos apoyan a sus padres en el campo y sus hogares para lograr mayores ingresos desde temprana edad (Ayala-Carrillo y Cárcamo-Toalá, 2012). No obstante, cabe notar que los niños guatemaltecos nacidos en México muestran una asistencia escolar mucho más alta que la de los niños guatemaltecos de primera generación; y similar a la de los niños mexicanos del sureste mexicano, aunque con indicios de rezago escolar en los primeros años de escolarización (Aguilar y Giorguli, 2016).

Enseguida describimos las variables socioeconómicas a nivel hogar (Tabla 3). Es importante señalar que la estructura de oportunidades de incorporación económica y el acceso a los servicios en la vivienda, se encuentra vinculada al nivel de urbanización de la localidad de residencia. En este sentido, los hogares guatemaltecos están en desventaja, ya que tienen una alta concentración en áreas rurales; los guatemaltecos HLI se ubican predominantemente en áreas rurales $(90 \%)$, seguidos por los guatemaltecos no HLI $(69 \%)$, cifras superiores a los de los mexicanos. 
La concentración rural de los guatemaltecos HLi puede resultar favorable en términos de tenencia de la vivienda, al disminuir los costos de la tierra. Así, un alto porcentaje de los hogares guatemaltecos HLI tiene vivienda propia $(77 \%)$, cifra más baja que entre los mexicanos HLI, pero comparable a la de los mexicanos no HLI (Tabla 3). En cambio, los guatemaltecos no HLI registran un bajísimo nivel de tenencia de la vivienda, solo 38\% tiene casa propia. Sin embargo, es importante señalar que aun cuando algunos guatemaltecos indígenas refugiados obtuvieron tierras para construir sus viviendas por donación o el apoyo por organizaciones civiles y religiosas, no se contempló la dotación de tierras de cultivo, lo cual ha contribuido a reproducir sus niveles de pobreza (Ruiz, 2018).

Además, entre los guatemaltecos el hacinamiento es más frecuente que entre los mexicanos, indicando la necesidad de viviendas más amplias, así como la precariedad de la vivienda (menor agua entubada) y la pobreza (medida a través de los bienes duraderos en la vivienda y de ingresos por trabajo), especialmente entre los guatemaltecos HLI. En este sentido, cabe señalar que los hogares mexicanos HLI también residen en viviendas precarias y en situación de pobreza, pero entre los guatemaltecos HLI esta situación es más grave.

Debido a la alta inserción económica de los hogares guatemaltecos en el campo mexicano y actividades del sector terciario, ambos con alta informalidad, se registra una muy alta falta de acceso a seguridad médica (24\% entre los HLi y $44 \%$ entre los no HLI) y muy pocos hogares guatemaltecos gozan de seguro médico por empleo. En cambio es muy alta la inserción en el Sistema de Protección Social en Salud, mejor conocido como Seguro Popular, llegando a ser más alta en el caso de los hogares HLI guatemaltecos que entre los HLI mexicanos. Esta situación laboral precaria coincide con la encontrada para los migrantes guatemaltecos en Chiapas a partir de la Encuesta sobre Migración en la Frontera Sur de México (emif Sur) 2004-2013 y los Censos de Población y Vivienda de 2000 y 2010 (Meza, 2015).

En cuanto a la dependencia económica al interior de los hogares, el menor porcentaje de trabajadores sobre los residentes en los hogares se ubicó en los hogares guatemaltecos HLI, a comparación de los demás tipos de hogar. No obstante, este porcentaje puede ser susceptible al ciclo de vida de los hogares y el análisis multivariado arrojar resultados diferentes.

Por último, la dependencia de subsidios económicos, en particular en apoyos gubernamentales (programas de gobierno) de los hogares guatemaltecos HLI es muy alta, llega a representar alrededor de $68 \%$, en comparación con $57 \%$ de los hogares mexicanos HLI. Sin embargo, esto no sucede en los hogares guatemaltecos no HLI, quienes solo $30 \%$ dependen de estos apoyos, en contraste con $44 \%$ de los mexicanos no HLI. Además, los hogares guatemaltecos reportan una mayor recepción de remesas internacionales que los hogares mexicanos, en especial los HLI. Al respecto, en diversas investigaciones se reporta la emigración a los Estados Unidos de los varones guatemaltecos asentados en México para lograr la subsistencia y la integración social de sus familias en el sur mexicano a través de las remesas para la compra de viviendas y tierras de cultivo (Kauffer, 2005; Ruiz, 2018). 


\section{Perfiles socioeconómicos de los hogares guatemaltecos por habla indígena}

En este apartado, resumimos los resultados de la regresión logística multinomial, que nos permite entender en su conjunto cuáles son los factores más importantes que definen el perfil socioeconómico de los hogares guatemaltecos por origen étnico (Tabla 4). La categoría de referencia de la variable dependiente son los hogares mexicanos no HLI, ya que son quienes constituyen el grupo mayoritario, y a quienes, de acuerdo con la perspectiva de la integración (Heckmann, 2003; 2006), deberían asemejarse los guatemaltecos al paso del tiempo en relación al acceso a instituciones y servicios.

Como control se introdujeron algunas variables relativas a la configuración de los hogares. En cuanto a la composición demográfica de los hogares guatemaltecos HLI, se corrobora una más baja propensión a tener jefatura femenina y un mayor número de hijos residentes que el resto de los tipos de hogares. Asimismo, estos son los hogares que presentan una mayor probabilidad de haber inmigrado recientemente, una vez que se controlan sus características demográficas y socioeconómicas. Por último, es menos probable que en estos hogares resida la pareja, en comparación con los hogares mexicanos no HLI.

Respecto al perfil laboral de los hogares guatemaltecos HLI, se confirma que tienen mayor probabilidad de tener jefes trabajando en actividades agropecuarias y menor probabilidad en el sector secundario y terciario, en comparación con no estar trabajando. Además, una vez controlado el sector de actividad, se registra un menor acceso a cualquier tipo de seguridad médica, ya sea por parte del empleador o por su afiliación al Seguro Popular. También se encuentra que el porcentaje de trabajadores en estos hogares es mayor que entre los mexicanos no HLI y que es más alta la probabilidad de tener hijos menores de 18 años sin estudiar, en lugar de que asistan a la escuela, lo cual - como vimos en el apartado anterior- coincide con una elevada inserción laboral de los hijos.

Las características de la vivienda revelan que los hogares guatemaltecos HLI se encuentran en mayores niveles de precariedad y pobreza. La posibilidad de estos hogares de residir en zonas urbanas es muy baja. Además, estos hogares tienen más bajas posibilidades de vivir en vivienda propia, de tener agua entubada dentro de la vivienda y presentan un menor número de bienes. Respecto al acceso a la vivienda, es importante señalar que una vez controlada la residencia rural, se evidenció su desventaja en términos de tenencia de la propiedad respecto a los mexicanos no HLI. Por último, se corrobora la mayor propensión de los hogares guatemaltecos HLI a recibir apoyos económicos gubernamentales y remesas internacionales.

¿Esta caracterización de los guatemaltecos HLI difiere del perfil de los guatemaltecos no HLI? Por un lado, se observan diferencias en la configuración de sus hogares respecto a los mexicanos no HLI. En los hogares guatemaltecos no HLI, resulta más alta la propensión a tener jefatura femenina y es menos probable estar sin pareja, aunque se sigue observando una relación positiva con un mayor número de hijos y una menor asistencia escolar de los hijos menores. También la inmigración reciente guarda una asociación fuerte y positiva con este tipo de hogares, a comparación de los hogares mexicanos no HLI. 
Tabla 4: Perfiles socioeconómicos asociados a los hogares por país de nacimiento y habla de lengua indígena (razones de riesgo relativo). Municipios seleccionados en frontera sur, México $(n=343273)$

\begin{tabular}{|c|c|c|c|}
\hline \multirow[t]{2}{*}{ Variables independientes } & Guatemaltecos & Guatemaltecos & Mexicanos \\
\hline & HLI & no HLI & HLI \\
\hline Edad del jefe & 1.000 & 1.000 & $1.002 * * *$ \\
\hline Jefe mujer (Hombre) & $0.666 * * *$ & $1.124 * *$ & $0.788 * * *$ \\
\hline Hijos residentes & $1.503 * * *$ & $1.081 * * *$ & $1.116^{* * *}$ \\
\hline $\begin{array}{l}\text { Migración reciente (No) } \\
\text { Sector de actividad del jefe } \\
\text { (No trabaja) }\end{array}$ & $6.053 * * *$ & $3.791 * * *$ & $0.534 * * *$ \\
\hline Primario & $1.141^{*}$ & $1.191^{* * *}$ & $1.255^{* * *}$ \\
\hline Secundario & $0.693 * * *$ & $1.229 * * *$ & 0.95 \\
\hline Terciario & $0.617 * * *$ & 0.972 & $0.782 * * *$ \\
\hline \multicolumn{4}{|l|}{$\begin{array}{l}\text { Pareja trabaja } \\
\text { (Con pareja-no trabaja) }\end{array}$} \\
\hline Sin pareja & $1.190 * *$ & $0.446^{* * *}$ & $0.773 * * *$ \\
\hline Con pareja- trabaja & 1.045 & 1.008 & $1.164 * * *$ \\
\hline \multicolumn{4}{|l|}{$\begin{array}{l}\text { Hijos menores asisten a escuela } \\
\text { (todos asisten) }\end{array}$} \\
\hline Sin hijos menores & $1.395 * * *$ & $0.762 * * *$ & $1.493 * * *$ \\
\hline Al menos uno no estudia & $1.714 * * *$ & $1.897 * * *$ & $1.109 * * *$ \\
\hline Urbano (rural) & $0.358 * * *$ & $0.604 * * *$ & $1.145^{* * *}$ \\
\hline \multicolumn{4}{|l|}{ Tenencia de vivienda (Renta) } \\
\hline Propia & $0.386^{* * *}$ & $0.218^{* * *}$ & $1.333 * * *$ \\
\hline Otra & $0.233 * * *$ & $0.564 * * *$ & $0.812 * * *$ \\
\hline Agua entubada dentro (No) & $0.629 * * *$ & $0.803 * * *$ & $0.683 * * *$ \\
\hline Hacinamiento & 0.959 & $1.188^{* * *}$ & $1.053^{* * *}$ \\
\hline Número de bienes & $0.894 * * *$ & $0.802 * * *$ & 1.001 \\
\hline$\%$ trabajadores & $1.010 * * *$ & $1.006^{* * *}$ & $1.003 * * *$ \\
\hline \multicolumn{4}{|l|}{$\begin{array}{l}\text { Seguridad Médica } \\
\text { (Sin seguridad) }\end{array}$} \\
\hline Solo Seguro Popular & $0.480 * * *$ & $0.257^{* * *}$ & $1.902 * * *$ \\
\hline Solo IMSS O ISSSTE & $0.178 * * *$ & $0.217 * * *$ & $2.101 * * *$ \\
\hline Ambos & $0.114 * * *$ & $0.252 * * *$ & $2.485^{* * *}$ \\
\hline Apoyo de gobierno (No) & $1.388 * * *$ & $0.593 * * *$ & $1.220 * * *$ \\
\hline Recibe remesas (No) & $1.644 * * *$ & $2.071 * * *$ & $0.731 * * *$ \\
\hline log-likelihood & & & -121455.7 \\
\hline
\end{tabular}

Fuente: Estimaciones propias con base en Encuesta Intercensal 2015 (Inegi, 2015).

Nota: $\mathrm{HLI}=$ Hablantes de lengua indígena. Categorías de referencia en paréntesis. Categoría de variable dependiente: hogares mexicanos no HLI.

${ }^{*} p<.05 ;{ }^{* *} p<.01 ;{ }^{* *} p<.001$ 
Por otro lado, los guatemaltecos no HLI tienden a vivir también en áreas rurales, aunque en menor medida que los guatemaltecos HLI, y a tener un comparable acceso a vivienda y a bienes y servicios que estos últimos. Sin embargo, el riesgo de hacinamiento es más alto y menor su probabilidad de recibir soporte gubernamental. En este sentido podríamos decir que también viven en condiciones de precariedad y que, además, al encontrarse en áreas más urbanas, tienen una reducida posibilidad de acceder a viviendas propias, así como de contar con transferencias públicas.

Respecto a las actividades económicas de los hogares guatemaltecos no HLI, se encuentra que se diversifica la inserción ocupacional de los jefes, se incorporan más tanto a la agricultura como al sector secundario, a diferencia de los hogares guatemaltecos HLI, quienes se insertan predominantemente en el sector primario. A pesar de que los guatemaltecos no HLI se ubican principalmente en el sector terciario, en términos relativos es mayor su inserción en los otros dos sectores respecto a los mexicanos no HLI.

¿Hay diferencias en los perfiles de los hogares guatemaltecos HLI y los hogares mexicanos HLI? Los perfiles demográficos son muy similares, a excepción de algunas variables. Los jefes de hogares mexicanos HLi tienen mayor edad que los guatemaltecos y las parejas tienen mayor participación económica, además su probabilidad de migración reciente es bajísima. También su inserción económica tiende a estar un poco más diversificada. Al igual que los guatemaltecos HLI, los mexicanos HLI tienden a trabajar más en la agricultura, pero registran una inserción similar en el sector secundario que los mexicanos no HLI. Además, las desventajas en asistencia escolar de los hijos menores no son tan amplias como en el caso de los guatemaltecos HLI.

En cuanto a las características socioeconómicas, se registran brechas a favor de los indígenas mexicanos. Por ejemplo, es más probable entre los indígenas mexicanos la residencia urbana y tener vivienda propia, y los bienes en la vivienda son comparables a los de los hogares mexicanos no HLI. Además, es más común que cuenten con Seguro Popular, seguro médico por el empleador, o ambos, situación que no ocurre entre los guatemaltecos indígenas.

\section{Conclusiones}

El objetivo de este artículo fue analizar los perfiles demográficos y socioeconómicos de estos hogares por habla de lengua indígena en los municipios de mayor concentración de asentamiento guatemalteco en la frontera sur de México, a partir de la Encuesta Intercensal 2015. La hipótesis presentada fue que los guatemaltecos indígenas tendrían una doble desventaja en su integración socioeconómica al ser migrantes internacionales e indígenas. En concordancia con este planteamiento, los resultados de este artículo muestran que en general los guatemaltecos presentan indicadores de integración socioeconómica más bajos que los mexicanos. Sin embargo, por la historia de los asentamientos de refugiados con fuerte componente indígena, y acorde a la naturaleza multidimensional de la integración socioeconómica (Heckmann, 2006), en ciertos rubros los guatemaltecos indígenas registran niveles más altos de integración social que los guatemaltecos no indígenas, en particular en el acceso a la naturalización y vivienda propia. 
Los resultados estadísticos indican que los guatemaltecos indígenas se concentran en áreas rurales y su participación económica se ubica predominantemente en la agricultura, lo cual los coloca en desventaja socioeconómica frente a los hogares mexicanos. Esta situación resulta evidente en diversos indicadores de integración socioeconómica como la seguridad social, los ingresos por trabajo y los bienes duraderos.

Así, con la ausencia de garantías laborales en el sector agrícola, muy pocos hogares guatemaltecos HLi gozan de seguro médico por empleo. Es muy alta la falta de seguro médico y más frecuente la afiliación en el Seguro Popular que entre los mexicanos (hablantes o no de lengua indígena). Además, la pobreza de los hogares es palpable en las condiciones de la vivienda. Esta situación los lleva a depender altamente de subsidios gubernamentales y remesas para lograr su sobrevivencia.

La situación socioeconómica de los hogares guatemaltecos no indígenas resulta similar a la de los guatemaltecos indígenas, aunque ligeramente ventajosa en algunos aspectos como la diversificación de sectores económicos en los que se insertan, los mayores ingresos por trabajo y la residencia un poco más urbana. Sin embargo, también se encuentran en trabajos precarios con escaso acceso a seguridad médica y, en comparación con los hogares guatemaltecos indígenas y los mexicanos, tienen muy bajo acceso a vivienda propia. Además, sus niveles de naturalización son muy bajos, lo cual podría estar limitando su acceso a servicios públicos y apoyos gubernamentales. A diferencia de los guatemaltecos indígenas, para quienes estar organizados en comunidades y vivir en ciertos territorios rurales pudo haber sido ventajoso para avanzar en estas dimensiones de la integración (Kauffer, 2005; Ruiz, 2018), los guatemaltecos no indígenas no se beneficiaron lo suficiente de las campañas de naturalización. Desgraciadamente no tenemos información sobre documentación migratoria en los censos de población como para conocer si regularizaron su estancia en México.

En cuanto a los perfiles demográficos, se notan aspectos distintivos de los hogares guatemaltecos en México, respecto a los mexicanos. Los hogares guatemaltecos son numerosos debido principalmente a su elevada fecundidad y se ubican en una etapa más temprana de ciclo de vida familiar. El análisis estadístico multivariado también arroja que existe una alta participación económica de los jefes y los hijos, lo que los lleva a tener una menor dependencia económica al interior de sus hogares que los mexicanos HLI. No obstante, esta dinámica de los hogares también limita la escolarización de los hijos, siendo más común tener hijos menores que han abandonado los estudios. Lo anterior aplica tanto a HLI, como no HLI. Por último, es necesario subrayar que existen diferencias demográficas de los hogares guatemaltecos de acuerdo al habla de lengua indígena. Los hogares guatemaltecos HLI tienen una muy baja jefatura femenina, son aún más numerosos y se ubican en una etapa del ciclo de vida familiar un poco más avanzada que los no HLI.

Estos hallazgos invitan a reflexionar sobre las necesidades de intervención pública a favor de los hogares guatemaltecos para lograr su plena integración social en territorio mexicano. Como lo señalan Coria y Zamudio (2018), al momento no existe una política para la integración de los inmigrantes en México, sino un ambiente institucional y social hostil que los discrimina y margina, limitando el ejercicio de sus derechos sociales.

En cuanto a los servicios de salud, es necesario hacer un análisis minucioso de las carencias en materia de salud de los hogares guatemaltecos, pues es muy alto el 
porcentaje de hogares sin seguridad médica. Además, dado que el Seguro Popular es el principal servicio de salud al que tienen acceso, habría que evaluar la calidad de estos servicios que se están ofreciendo a esta población. Los resultados sugieren que la alta fecundidad podría estar ligada a un bajo acceso a métodos anticonceptivos, principal factor asociado a la fecundidad en México, lo cual pudiese inhibir la capacidad de agencia en la toma de decisiones reproductivas de las mujeres guatemaltecas.

Otro hallazgo del estudio fueron las escasas oportunidades educativas para los jóvenes guatemaltecos. Estos jóvenes desertan de la escuela a edad temprana para auxiliar a los padres, como puede percibirse en su alta participación económica. Una intervención pública podría estar enfocada a la promoción de becas de educación media superior entre este sector, así como la expansión de oferta escolar flexible y de bachilleratos y carreras técnicas que estimulen la productividad de las actividades agropecuarias que realizan, así como el emprendimiento de negocios de acuerdo al mercado laboral de la región.

También es latente que las condiciones en las que viven los guatemaltecos son muy precarias. Por un lado, los indígenas, quienes viven en áreas de baja urbanización y con predominio de actividades agropecuarias, presentan mayor hacinamiento y tienen bajo acceso a servicios públicos y bienes duraderos. Por otro lado, los no indígenas, aunque viven en áreas más urbanas, poseen muy bajo acceso a vivienda propia. En este sentido, es necesario impulsar un programa de acceso y mejoramiento de las viviendas a favor de este sector poblacional que vive en condiciones de marginación socioeconómica.

Las dificultades que enfrentan los guatemaltecos para su integración en México plantean la necesidad de proyectos productivos en el sur del país. El modelo de desarrollo actual se ha enfocado en la redistribución de la riqueza a través de transferencias monetarias, sin cambiar de fondo las condiciones de inequidad y dependencia económica. Sin embargo, es necesario promover el desarrollo económico regional, diversificando las fuentes de empleo, con salarios dignos y mejores condiciones laborales. La inmigración de centroamericanos de distintas nacionalidades podría elevarse en las fronteras de México - tanto sur como norte- en esta era de expulsiones (Sassen, 2014), por lo que promover la inversión económica, ya sea pública o privada, en las regiones hacia donde se están dirigiendo estos migrantes debe considerarse prioridad nacional.

Cabe mencionar que la concentración geográfica de los guatemaltecos en ciertos municipios de Chiapas, Campeche y Quintana Roo podría facilitar la focalización de estrategias de intervención para su integración socioeconómica. Por ejemplo, si bien la población guatemalteca indígena se encuentra segregada en áreas rurales, su situación nos indica la necesidad de políticas públicas a favor del agro mexicano en estas entidades. En este sentido, más allá de dar cartillas provisionales de asilo o refugio a los migrantes centroamericanos, se deben diseñar políticas públicas que permitan su incorporación en México, que no los confinen a la segregación geográfica y la marginación socioeconómica. Esta es una lección que aplica tanto a los mismos guatemaltecos como a las nuevas oleadas de inmigrantes que están arribando a este país, ya que requerirán de la implementación de políticas públicas para su desarrollo y de su seguimiento al paso del tiempo. 


\section{Agradecimientos}

Se agradece al proyecto Región Transfronteriza México-Guatemala, financiado por el Conacyt, el apoyo financiero otorgado para la elaboración de este estudio (http:/ / www.rtmg.org/). Asimismo, se agradece la asistencia técnica de Fátima Valdez en la sistematización bibliográfica.

\section{Referencias}

Aguilar, R. y Giorguli, S. (2016). Escolaridad en niños y jóvenes centroamericanos en México: Generaciones 1.5 y 2.0. (CANAmid Policy Brief Series, 10). Guadalajara, México: CIESAS.

Ayala-Carrillo, M. y Cárcamo-Toalá, N. J. (2012). Los niños y niñas guatemaltecas migrantes en la frontera sur de México: Acompañantes o trabajadores. Ra Ximhai, $8(1), 29-44$.

Castillo, M. A. y Toussaint, M. (2015). La frontera sur de México: Orígenes y desarrollo de la migración centroamericana. Cuadernos Inter.c.a.mbio sobre Centroamérica y el Caribe, 12(2), 59-86. https://doi.org/10.15517/C.A..V12I2.21700

Castillo, M. A. y Vázquez, M. (2010). Los inmigrantes guatemaltecos en México: Antecedentes históricos y situación actual. En E. Rodríguez y S. Herrera (Coord.), Extranjeros en México. Continuidades y nuevas oportunidades (pp. 237-273). México: Instituto Nacional de Migración.

Chan, L. y García, M. (2018). In Search of Other Borders: Guatemalan-Mexican. Communities in Southern Mexico. Frontera Norte, 30(59), 5-28.

Comisión Nacional para el Desarrollo de los Pueblos Indígenas/ Programa de las Naciones Unidas para el Desarrollo (2006). Regiones indígenas de México. Ciudad de México: CDI/PNud. Recuperado de: http://www.cdi.gob.mx/regiones/regiones_indigenas_cdi.pdf

Coria, E. y Zamudio, P. (2018). Inmigrantes y refugiados: ¿ Mi casa es tu casa?. Mexico D. F.: CIDE-Programa Interdisciplinario en Estudios Migratorios.

Del Popolo, F. (2017). Los pueblos indígenas en América (Abya Yala): desafíos para la igualdad en la diversidad. Santiago, Chile: Comisión Económica para América Latina y el Caribe (CEPAL).

Duarte, R. y Coello, T. (2007). La decisión de marcharse: Los pueblos indígenas migrantes de Guatemala y Chiapas. Guatemala: Consejería en Proyectos 2007. Recuperado de https://www.fundacionhenrydunant.org/images/stories/biblioteca/ ddhh-migracion-refugio/Decisi\%C3\%B3n\%20de\% 20marcharse \% 20Migraci\%C3\%B3n\%20guatemalteca.PDF

Esser, H. (2004). Welche Alternativen zur, Assimilation' gibt es eigentlich? En K. J. Blade y M. Bommes (Coords.), Migration-Integration-Bildung: Grundfragen und Problembereiche (pp. 41-60). Osnabrück, Alemania: Eigenverlag IMIs.

González, A. (2015). Integración en localidades rurales. Ex refugiados guatemaltecos naturalizados mexicanos en los municipios fronterizos de La Trinitaria y Frontera Comalapa, Chiapas. (Tesis de doctorado en Antropología de Iberoamérica), Universidad de Salamanca. Recuperado de: 
https://gredos.usal.es/jspui/bitstream/10366/128334/1/III_Gonz\%C3\%A1lezRojasA_Integraci\%C3\%B3nlocalidades.pdf

Heckmann, F. (2003). From ethnic nation to universalistic immigrant integration. En F. Heckmann y D. Schnapper (Coords.), The integration of immigrants in European societies (pp. 45-78). Stuttgart, Alemania: De Gruyter Olderbourg.

Heckmann, F. (2006). Integration and integration policies: IMISCOE network feasibility study. Bamberg, Alemania: Institute at the University of Bamberg. Recuperado de https:// nbn-resolving.org/urn:nbn:de:0168-ssoar-192953

Hernández, A. (2012). Nuevas identidades en la frontera Chiapas-Guatemala: Migración y relaciones de género en regiones indígenas. En Estado del desarrollo económico y social de los pueblos indígenas de Chiapas. México: unam y Secretaría de Pueblos y Culturas Indígenas del Gobierno del Estado de Chiapas. Recuperado de: http://www.nacionmulticultural.unam.mx/edespich/images/diagnostico_y_perspectivas/Sistema_de_justicia_y_movimientos_indigenas/Migraciones_indigenas_en_el_chiapas_contemporaneo/recuadros/1_nuevas_identidades_en_la_frontera.pdf

Inegi. (2001). Censo de Población y Vivienda 2000. Microdatos.

Inegi. (2015). Encuesta Intercensal 2015. Microdatos.

Inegi. (2019). Glosario. Recuperado de: https://www.inegi.org.mx/app/glosario/default.html? $\mathrm{p}=$ censos 2005

Jelin, E. (1991). Everyday practices, family structures, social processes. En E. Jelin (Ed.), Family, household and gender relations in Latin America (pp. 1-5). Gran Bretaña: Unesco.

Kauffer, E. F. (2000). Refugiados guatemaltecos en México: Del refugio a la repatriación, del retorno a la integración. Boletín de Migración Internacional, 4(12), 7-12. Recuperado de https://www.researchgate.net/publication/319422713_Refugiados_guatemaltecos_en_Mexico_del_refugio_a_la_repatriacion_del_retorno_a_la_integracion

Kauffer, E. F. (2005). De la frontera política a las fronteras étnicas: refugiados guatemaltecos en México. Frontera Norte, 17(34), 7-36.

Lerma, E. (2016). Guatemalteco-mexicano-estadounidenses en Chiapas: Familias con estatus ciudadano diferenciado y su multiterritorialidad. Migraciones Internacionales, 8(3), 95-124.

López, A. (2001). El perfil sociodemográfico de los hogares en México 1976-1997. En Conapo, La situación demográfica de México (pp. 10-11). México, D. F.: Consejo Nacional de Población.

Meza, L. (2015). Visitantes y residentes: Trabajadores guatemaltecos, salvadoreños y hondureños en México. Canamid Policy Brief Series, 4. Guadalajara, México: ciesas.

Nájera, J. (2017). Migración, fuerza de trabajo y familia, elementos en la definición del espacio transfronterizo México-Guatemala. EntreDiversidades, (8), 119-150. Recuperado de: http://entrediversidades.unach.mx/index.php/entrediversidades/article/view/24/55

Ramos, D. N. (2013). Un pie en ambos lados: la vida cotidiana de los trabajadores migrantes en la frontera sur (Tesis de maestría). Maestría en Comunicación de la Ciencia y la Cultura). Instituto Tecnológico y de Estudios Superiores de Occidente. Recu- 
perado de https://rei.iteso.mx/bitstream/handle/11117/2514/tesis-diego-ramos-octubre 2013.pdf?sequence $=2$

Rivera, C. (2014). Introducción. En C. Rivera (Coord.), Trabajo y vida cotidiana de centroamericanos en la frontera suroccidental de México (pp. 6-16). México, D. F.: cIEsas.

Robichaux, D. (2002). El sistema familiar mesoamericano y sus consecuencias demográficas: un régimen demográfico en el México indígena. Papeles de población, 8(32), 59-94.

Rodríguez, E. (2016). Migración centroamericana en tránsito irregular por México: nuevas cifras y tendencias, CANAMID Policy Brief Series, 14. Guadalajara, México: ciesas.

Rodríguez, M. T. y Caballeros, A. (2020). Más allá de la frontera. Movilidad y reconfiguraciones familiares entre los chuj de México y Guatemala. Frontera Norte, 32, 1-28 (por publicar).

Ruiz, V. (2011). Los Promotores de educación como actores claves en la educación comunitaria. El caso de los chujes, kanjobales y acatekos de origen guatemalteco en Chiapas, México. Ponencia presentada en el vir Foro Latinoamericano de Educación Intercultural, Migración y Vida Escolar organizado por Educación Contracorriente A.C. Cuetzalan, Puebla.

Ruiz, V. (2018). Los refugiados guatemaltecos y la frontera-frente de discriminación, explotación y desigualdad. Alteridades, 28(56), 47-57.

Sassen, S. (2014). Expulsions. Brutality and complexity in the global economy. Boston, MA: Harvard University Press.

Torrado, S. (1981). Sobre los conceptos de estrategias familiares de vida y proceso de reproducción de la fuerza de trabajo. Notas teórico-metodológicas. Demografía y Economía, 15(2), 204-233.

Vázquez, G. y Félix, M. (2015). Los indígenas autoadscritos de México en el censo 2010: ¿revitalización étnica o sobreestimación censal? Papeles de Población, 21(86), 171-218.

Eunice D. Vargas Valle

Mexicana. Doctora en Sociología con especialidad en Demografía por la Universidad de Texas en Austin, Estados Unidos. Profesora-investigadora en el Departamento de Estudios de Población de El Colegio de la Frontera Norte. Sus líneas de investigación son: la sociodemografía de la niñez y juventud, con énfasis en educación, migración y familia, así como la demografía regional. Publicación reciente: Vargas-Valle, E. D. y Orraca-Romano, P. (2018). La reinserción en la escuela y su vinculación con la vida familiar y laboral de tres generaciones de mexicanos, Papeles de población, 24(97), 227-254. 
Oscar Rodríguez Chávez

Mexicano. Estudiante del Doctorado en Estudios de Población de El Colegio de México y Maestro en Desarrollo Regional por El Colegio de la Frontera Norte. Ha trabajado como investigador del Observatorio Nacional Ciudadano (ONC) en la elaboración de reportes sobre incidencia delictiva en México. También ha trabajado como asistente de investigación para El Colef en proyectos sobre migración, educación y desigualdad. Participa como articulista para el Blog onc del Universal Opinión. Publicación reciente: Masferrer, C. y Rodríguez, O. (2019). Migración y violencia: Cambios en la migración interna e internacional en México. Otros Diálogos, (7).

María Teresa Rodríguez López

Mexicana. Doctora en Ciencias Antropológicas por la Universidad Autónoma Metropolitana. Profesora-investigadora del ciesas-Golfo, con sede en Xalapa, Veracruz, México Líneas de investigación: dinámicas interétnicas, identidades y movilidades en el área mesoamericana, migración centroamericana. Publicación reciente: Rodríguez, M. T. (2018). Violencia sin tregua. Hondureños en la región del Golfo de México. Autoctonía. Revista de Ciencias Sociales e Historia, II(1), 92-107. 